\title{
Fluid Therapy Rate in Postrenal Azotemia Stabilization in Cats
}

\author{
Marina Gabriela Monteiro Carvalho Mori da Cunha ${ }^{1}$, Alceu Gaspar Raiser ${ }^{1}$, Danieli Brolo \\ Martins $^{2}$, Sonia Terezinha dos Anjos Lopes ${ }^{2}$, Gabrielle Coelho de Freitas ${ }^{1}$, Diego Vilibaldo \\ Beckmann" ${ }^{1}$, João Paulo Monteiro Carvalho Mori da Cunha, Luciele Varaschini Teixeira ${ }^{2}$, Adriano \\ Bonfim Carregaro ${ }^{3}$ and Ney Luis Pippi ${ }^{1}$
}

${ }^{1}$ Laboratory of Experimental Surgery, College of Veterinary Medicine, Federal University of Santa Maria, Santa Maria, 97105-900, Brazil ${ }^{2}$ Laboratory of Veterinary Clinical Pathology, College of Veterinary Medicine, Federal University of Santa Maria, Santa Maria, 97105-900, Brazil ${ }^{3}$ Department of Veterinary Medicine, University of São Paulo, Pirassununga, São Paulo, Brazil

Received: August 07, 2016; Accepted: September 01, 2016; Published: September 07, 2016

*Corresponding author: Marina Gabriela Monteiro Carvalho Mori da Cunha, Laboratory of Experimental Surgery, College of Veterinary Medicine, Federal University of Santa Maria, Santa Maria, 97105-900, Brazil, E-mail: biamori@gmail.com

\begin{abstract}
Fluid therapy is the most important component involved in the stabilization of postrenal azotemia, however there is not yet a consensus about the ideal rate of fluid therapy after relief of urethral obstruction. Fifteen adult cats were divided in two groups: High Rate Group (HRG) and Low Rate Group (LRG). At predetermined time points was assessed venous blood $\mathrm{pH}, \mathrm{pCO}_{2} \mathrm{pO}_{2}$, bicarbonate concentration, $\mathrm{BE}$, creatinine, $\mathrm{BUN}, \mathrm{Na}^{+}, \mathrm{K}^{+}$and urinary output. HRG had a lower glomerular filtration rate, characterized by a lower urinary output and a slower stabilization of BUN, creatinine, acidbase balance and potassium. The infusion of high rates of fluids in cats after a urethral obstruction must be undertaken with caution since it can lead to death due to the occurrence of pleural effusion and the absence of appropriate restoration of electrolyte balance and glomerular filtration.
\end{abstract}

Keywords: Acid-base balance; Azotemia; Fluid therapy

Urethral Obstruction (UO) is one of the most common emergencies involving the urinary tract in cats [1]. Death may occur as a result of cardiopulmonary failure, water-electrolyte imbalance or acute renal failure [2]. Fluid therapy is the most important component involved in the stabilization of postrenal azotemia because it alleviates hyperkalemia, acidosis, and azotemia in most instances [3]. It is recommended that administration of fluids commence as soon as possible to correct the water-electrolyte balance and replace urinary losses due to dehydration and post obstructive dieresis $[1,3,4]$. Inadequate replacement of fluids during the post obstructive period can delay resolution of these electrolytic, acid-base and uremic disturbances [4]. Moreover it can impair the kidney perfusion due to the hypovolemia $[2,4]$.

Fluid flux between compartments is determined by the balance between their hydrostatic and oncotic forces [5]. The imbalance of these forces causes edema, ascites, pleural effusions and so forth (i.e., "third spacing"). This, in turn, may result in a relative decrease in the intravascular circulating blood volume and lead to insufficient perfusion and organ dysfunction [6].
Metabolic acidosis may enhance hyperkalemic cardiotoxicity and venoconstriction, which, in turn, might promote clinical signs of fluid overload after intravenous administration of small fluid volumes [4]. There is not yet a consensus about the ideal rate of fluid therapy after relief of UO. Suggestions range between 10$90 \mathrm{ml} / \mathrm{kg} / \mathrm{h}$ for initial therapy in severe cases $[1,4,7]$.

The aim of the present paper was to alert veterinary clinicians about the influence of high rate of fluid therapy in the stabilization of cats with UO.

This study was a pilot study from two other studies $[8,9]$. Fifteen neutered male adult mixed breed cats (weight range 3 to $5 \mathrm{~kg}$ ) were housed in individual cages, fed dry commercial food and water was available ad libitum. The 15 cats were randomly allocated to receive a different rate of fluid therapy, with 5 cats in the High Rate Group (HRG) and 10 cats in the Low Rate Group (LRG). The initial rate for HRG was $40 \mathrm{~mL} / \mathrm{kg} / \mathrm{h}$ from 0 to 2 hours; this rate was reduced to $20 \mathrm{~mL} / \mathrm{kg} / \mathrm{h}$ from 2 to 12 hours, $15 \mathrm{~mL} /$ $\mathrm{kg} / \mathrm{h}$ from 12 to 24 hours, and $10 \mathrm{~mL} / \mathrm{kg} / \mathrm{h}$ from 24 to 48 hours. The initial rate for LRG was $20 \mathrm{~mL} / \mathrm{kg} / \mathrm{h}$ from 0 to 6 hours; this rate was reduced to $15 \mathrm{~mL} / \mathrm{kg} / \mathrm{h}$ from 6 to 12 hours, $10 \mathrm{~mL} / \mathrm{kg} / \mathrm{h}$ from 12 to 24 hours, and $5 \mathrm{~mL} / \mathrm{kg} / \mathrm{h}$ from 24 to 48 hours.

All experimental procedures were reviewed and approved by the Federal University of Santa Maria Animal Care and Use Committee, number 031-2008. The animals were submitted to a urethral obstruction model $[8,9]$ (parallel study) and submitted to the anesthetic for relieving of urethral obstruction when any 3 of 4 clinic pathologic criteria were met: venous $\mathrm{pH}<7.2$, BUN concentration $>200 \mathrm{mg} / \mathrm{dL}$, serum creatinine concentration $>$ $4.5 \mathrm{mg} / \mathrm{dL}$, and serum potassium concentration $>6.5 \mathrm{mEq} / \mathrm{L}$.

At predetermined time points, a blood sample was collected from the jugular vein to assess venous blood $\mathrm{pH}, \mathrm{pCO}_{2}, \mathrm{pO}_{2}$, bicarbonate concentration, $\mathrm{BE}$, creatinine, BUN, sodium and potassium. The animals were weighed before urethral catheter placement and at 2, 4, 6, 8, 12 and 24 hours after UO removal. Venous blood gases, serum electrolyte analyses, creatinine and 
BUN were performed at baseline, SFT, 2, 8, 12, 24, and $48 \mathrm{~h}$. The urine from the low-vacuum drainage system was measured at 2 , $4,6,8,12,24$, and 48 h to estimate the urinary output.

In three different animals from the HR group, the albumin concentration was measured at $2 \mathrm{~h}, 12 \mathrm{~h}, 48 \mathrm{~h}$ and the analysis of pleural effusion was performed in two animals. In all LRG animals the albumin concentration was measured (data not shown).

Cats received meloxicam ${ }^{\mathrm{b}}(0.1 \mathrm{mg} / \mathrm{kg}$, IM, q $24 \mathrm{~h})$ from the day the occluded urethral catheter was placed until 3 days after the removal of the UO. In one animal from the HRG, fluid therapy was interrupted due to the evidence of fluid overload at $12 \mathrm{~h}$ of treatment. Therefore, furosemide ${ }^{\mathrm{c}}(2 \mathrm{mg} / \mathrm{kg} \mathrm{q} 8 \mathrm{~h} / 24 \mathrm{~h})$, Hydroxyethyl Starch ${ }^{d}(10 \mathrm{ml} / \mathrm{kg} / \mathrm{h} \mathrm{q12/} 48 \mathrm{~h})$, parenteral nutrition ${ }^{\mathrm{e}}$ were administered and thoracocentesis $(18 \mathrm{ml} / \mathrm{kg}$ of effusion) was performed to alleviate the fluid overload symptoms.

All analyses were performed with standard software ${ }^{\mathrm{f}}$. A repeated-measurement ANOVA was used followed by the Dunnett test to compare the mean of each variable (except urinary output) at the various time points with the baseline mean value within a group. Between groups, values for each variable at each time point were compared by use of a Student t-test. A value of $\mathrm{P}<0.05$ was considered significant. Results were expressed as mean $\pm \mathrm{SD}$.

Four out of five cats from the HRG died, two of them $36 \mathrm{~h}$ after the removal of UO and two after $72 \mathrm{~h}$. Necropsy revealed abdominal and thoracic effusion in all animals, as well as a straw yellow color with a limpid aspect, $\mathrm{pH} 7.0,100 \mathrm{mg} / \mathrm{dl}$ total protein and density 1,016. All animals started to show signs of dyspnea 12-24 h after the beginning of fluid therapy. Only one cat of the HRG survived after treatment of fluid overload. The respiratory pattern of this animal improved significantly after thoracocentesis and no dyspnea was observed after treatment. All cats from HRG developed fluid overload, evidenced by an increased body weight (Table 1) associated with clinical signs of dyspnea and ascites. Only one cat from the HRG survived due to symptomatic therapy, namely thoracocentesis, which improved lung function, the administration of colloids, which restored oncotic pressure, and the suspension of fluid to avoid a further increase in hydrostatic pressure.

Initially we attempted to administer a high rate of fluid because glomerular filtration is directly dependent on renal perfusion. Therefore an increase in blood volume might result in an increased urine output [6] and consequently a higher tubular excretion of potassium and uremic toxins [7]. However, even with the higher fluid rate, creatinine and BUN levels did not stabilize more rapidly in the HRG than in the LRG. We hypothesize that this group had a lower glomerular filtration rate, characterized by a lower urinary output and a slower stabilization of BUN, creatinine, acid-base balance and potassium. When comparing the two groups, the HRG had a higher concentration of BUN $(P<$ $0.05)$ and creatinine $(P<0.05)$ at $8,12,24$ and $48 \mathrm{~h}$. In the LRG, creatinine levels stabilized to reference values at $12 \mathrm{~h}$ whereas in the HRG levels did not normalize until the end of the evaluation.

The albumin concentration of the three animals from HRG was 1.22 (61\% of baseline), 1.03 (45\% of baseline) and 0.87
( $40 \%$ of baseline) at 2, 12 and $48 \mathrm{~h}$ respectively. In the same period, albumin levels in the LR group were $1.6 \pm 0.4,1.5 \pm 0.3$ and $1.5 \pm 0.4$, respectively. Infusion of crystalloid fluids alone can dilute serum albumin and other proteins and increase the risk of interstitial edema [10]. Possibly this hemodilution played an important role in the accumulation of fluid in third spacing in the HRG, whereas animals in the HRG had extremely low values of albumin and therefore were at risk for extravasation of fluid from the vascular space resulting in interstitial edema, as soon as serum albumin levels drop below $2.0 \mathrm{~g} / \mathrm{dl}$ [5].

Despite a higher rate of fluid being infused, the HRG had a lower urinary output $(P<0.05)$ than LRG at 4, 6, 8, 12 and $24 \mathrm{~h}$. We hypothesize that this occurred due to rapid fluid leakage into third spacing. This led to a greater increase in weight in the HRG than the LRG in the same time periods [6].

Analyses of venous blood gases showed that the HRG had a significantly lower $\mathrm{pH}(P<0.05)$ compared to the LRG at the 8, 12 and $24 \mathrm{~h}$ (Table 2$)$. The $\mathrm{pH}$ of the HRG was lower $(P<0.05)$ than baseline only at $0 \mathrm{~h}$ and it returned to the reference value at 48 $\mathrm{h}$. The $\mathrm{pH}$ of the LR group was significantly reduced compared to baseline at $0 \mathrm{~h}$ but normalized at $8 \mathrm{~h}$. Metabolic acidosis observed in the HRG did not stabilize until $24 \mathrm{~h}$ probably because $\mathrm{H}^{+}$ions were not excreted by the kidney due to an insufficient glomerular filtration rate. Furthermore, tissue perfusion may have been low due to the edema [11], which leads to the production of nonvolatile catabolites, such as lactate and ketone-bodies.

Since the animals in the HRG had dyspnea and tachypnea in an attempt to compensate for the metabolic acidosis and pleural effusion, the HRG had significantly lower $\mathrm{pCO}_{2}$ compared to LRG at $24 \mathrm{~h}$. The HRG had lower $\mathrm{HCO}_{3}$ and $\mathrm{BE}(P<0.05)$ compared with the LRG at $8,12,24$ and $48 \mathrm{~h}$. This group also had lower $\mathrm{HCO}_{3}$ and $\mathrm{BE}$ values than baseline at $0,2,8,12$ and $24 \mathrm{~h}$, while this was the case in the LRG only at 0 and 2 h. Even though a solution with the precursor for bicarbonate was infused, the HRG did not present stabilization of $\mathrm{HCO}_{3}$ and $\mathrm{BE}$ until $24 \mathrm{~h}$ and 48 $\mathrm{h}$ respectively, probably due to consumption of bicarbonate as a result of metabolic acidosis.

Potassium concentration normalized at $8 \mathrm{~h}$ in the LRG but only at $48 \mathrm{~h}$ in the HRG. The HRG had a higher potassium concentration than LRG at 8, 12 and $24 \mathrm{~h}$, probably due to a lower glomerular filtration rate and acidaemia, which lead to cation exchange with $\mathrm{H}^{+}$ions $[2,12]$.

The HRG presented hyponatremia (reference values) at 0,2 , $8,12,24$ and $48 \mathrm{~h}$. However only at 2, 8 and $24 \mathrm{~h}$ were values significantly lower $(P<0.05)$ compared to baseline. Decreased sodium values were only observed at 0 and $2 \mathrm{~h}$ in the LRG. Hyponatremia is the most common accompanying electrolyte imbalance observed with fluid overload ${ }^{7}$ because the increase in vascular volume leads to salt and water excretion by the kidney to restore the blood volume level [6].

The fluid accumulation in third spacing delays and impedes water-electrolyte and acid-base balance; in addition it leads to impaired cellular oxygen delivery and enzyme function, impaired cellular oxygen exchange, cellular swelling and cellular lysis, 
Table 1: Results of urine output, weight, BUN and creatinine in cats with experimentally induced UO that were treated IV with low rate of lactate ringer $(n=10)$ or high rate (5) following relief of UO.

\begin{tabular}{|c|c|c|c|c|c|}
\hline Time point & Treatment group & Urine output $(\mathrm{mL} / \mathrm{kg} / \mathrm{h})$ & Weight (percentage of baseline value) & BUN (mg/ dL) & $\begin{array}{l}\text { Serum creatinine (mg/ } \\
\text { dL) }\end{array}$ \\
\hline \multirow[t]{2}{*}{ Baseline } & HR & NM & $100 \pm 0.0$ & $49 \pm 16$ & $1.5 \pm 0.3$ \\
\hline & LR & NM & $100 \pm 0.0$ & $51 \pm 16$ & $1.3 \pm 0.2$ \\
\hline \multirow[t]{2}{*}{$\mathbf{0 ~ h}$} & HR & NM & $97 \pm 0.6$ & $318 \pm 109^{*}$ & $10 \pm 4^{*}$ \\
\hline & LR & NM & $96,8 \pm 3.9$ & $297 \pm 88^{*}$ & $7.2 \pm 1.9^{*}$ \\
\hline \multirow[t]{2}{*}{$2 \mathrm{~h}$} & HR & $12.9 \pm 3$ & $99,5 \pm 1.6$ & $286 \pm 106^{*}$ & $9.5 \pm 5.2^{*}$ \\
\hline & LR & $14.2 \pm 7.2$ & $97,5 \pm 3.1$ & $262 \pm 80^{*}$ & $5.1 \pm 1.3^{*}$ \\
\hline \multirow[t]{2}{*}{$4 \mathrm{~h}$} & HR & $8 \pm 4.6 \dagger$ & $102 \pm 1.3 \dagger$ & NM & NM \\
\hline & LR & $15.9 \pm 5.1 \dagger$ & $98.5 \pm 3 \dagger$ & NM & NM \\
\hline \multirow[t]{2}{*}{$6 \mathrm{~h}$} & HR & $6.3 \pm 3 \dagger$ & $104.3 \pm 0.2 * \dagger$ & NM & NM \\
\hline & LR & $16.6 \pm 6 \dagger$ & $98.9 \pm 3.4 \dagger$ & NM & NM \\
\hline \multirow[t]{2}{*}{$8 \mathrm{~h}$} & HR & $7.2 \pm 0.7 \dagger$ & $105.9 \pm 1.2 * \dagger$ & $307 \pm 104^{*} \dagger$ & $10.5 \pm 4.7^{*} \dagger$ \\
\hline & LR & $15.7 \pm 5 \dagger$ & $99.5 \pm 2.6 \dagger$ & $147 \pm 65^{*} \dagger$ & $2.7 \pm 1 \dagger$ \\
\hline \multirow[t]{2}{*}{$12 \mathrm{~h}$} & HR & $6.7 \pm 0.7 \dagger$ & $109.7 \pm 2.1^{*} \dagger$ & $242 \pm 115^{*} \dagger$ & $7.6 \pm 4.4^{*} \dagger$ \\
\hline & LR & $13.7 \pm 4.7 \dagger$ & $99.6 \pm 2.9 \dagger$ & $104 \pm 55 \dagger$ & $1.9 \pm 0.7 \dagger$ \\
\hline \multirow[t]{2}{*}{$24 \mathrm{~h}$} & HR & $7 \pm 1.3 \dagger$ & $116.7 \pm 3.8^{*} \dagger$ & $199 \pm 151 \dagger$ & $5.5 \pm 4.3 \dagger$ \\
\hline & LR & $10.3 \pm 2 \dagger$ & $98.6 \pm 3.4 \uparrow$ & $54 \pm 28 \dagger$ & $1.3 \pm 0.4 \dagger$ \\
\hline \multirow[t]{2}{*}{$48 \mathrm{~h}$} & HR & $8.4 \pm 2.1 \dagger$ & NM & $148 \pm 90 \dagger$ & $3.7 \pm 3.7 \dagger$ \\
\hline & LR & $4.5 \pm 1.3 \dagger$ & NM & $52 \pm 17 \dagger$ & $1.3 \pm 0.3 \dagger$ \\
\hline
\end{tabular}

Table 2: Results of venous blood gas and electrolyte analyses in cats with experimentally induced UO that were treated IV with low rate of lactate ringer $(n=10)$ or high rate (5) following relief of UO.

\begin{tabular}{|c|c|c|c|c|c|c|c|c|}
\hline Time point & $\begin{array}{l}\text { Treatment } \\
\text { group }\end{array}$ & Blood pH & $\begin{array}{l}\mathrm{pCO}_{2} \\
(\mathrm{~mm} \mathrm{Hg})\end{array}$ & $\begin{array}{l}\mathrm{pO}_{2} \\
(\mathrm{~mm} \mathrm{Hg})\end{array}$ & $\begin{array}{l}\text { Bicarbonate } \\
\text { (mmol/L) }\end{array}$ & Base excess & $\begin{array}{l}\text { Potassium } \\
(\mathrm{mEq} / \mathrm{L})\end{array}$ & $\begin{array}{l}\text { Sodium } \\
(\mathrm{mEq} / \mathrm{L})\end{array}$ \\
\hline \multirow[t]{2}{*}{ Baseline } & HR & $7.32 \pm 0.06$ & $35.5 \pm 3.7$ & $49.3 \pm 30.2$ & $17.8 \pm 1.8$ & $-2.9 \pm 8.8$ & $4.2 \pm 0.6$ & $155 \pm 2$ \\
\hline & LR & $7.31 \pm 0.01$ & $36.7 \pm 4.4$ & $39.7 \pm 7.1$ & $18.2 \pm 1.9$ & $-7.2 \pm 1.4$ & $3.9 \pm 0.4$ & $159 \pm 5$ \\
\hline \multirow[t]{2}{*}{$\mathbf{O h}$} & HR & $7.18 \pm 0.06^{*}$ & $35.8 \pm 5.3$ & $39.2 \pm 8.9$ & $12.7 \pm 0.9^{*}$ & $-14.9 \pm 2.2^{*}$ & $6.7 \pm 1.2^{*}$ & $147 \pm 4$ \\
\hline & LR & $7.14 \pm 0.08^{*}$ & $33.9 \pm 4.7$ & $42.5 \pm 7.5$ & $11.4 \pm 2.0^{*}$ & $-16.5 \pm 3.0^{*}$ & $7.1 \pm 1.2^{*}$ & $151 \pm 5^{*}$ \\
\hline \multirow[t]{2}{*}{$2 \mathrm{~h}$} & HR & $7.24 \pm 0.11$ & $32.3 \pm 6.8$ & $41.6 \pm 6.4$ & $13.4 \pm 1,7^{*}$ & $-12.7 \pm 3.3^{*}$ & $5.8 \pm 1.2$ & $145 \pm 2 * \dagger$ \\
\hline & LR & $7.22 \pm 0.09$ & $34.6 \pm 6$ & $41.9 \pm 11.3$ & $13.7 \pm 1,1^{*}$ & $-13 \pm 2.5^{*}$ & $5.4 \pm 1.2$ & $153 \pm 6^{*}+$ \\
\hline \multirow[t]{2}{*}{$8 \mathrm{~h}$} & HR & $7.18 \pm 0.12 \dagger$ & $34.7 \pm 9,9$ & $47.5 \pm 1,9 \dagger$ & $12.3 \pm 0,7^{*} \dagger$ & $-14.7 \pm 2.3^{*} \dagger$ & $6.5 \pm 0.1 \dagger$ & $144 \pm 3^{*} \dagger$ \\
\hline & LR & $7.33 \pm 0.06 \dagger$ & $32.3 \pm 5.2$ & $39.4 \pm 5.7 \dagger$ & $16.7 \pm 1.8 \dagger$ & $-8.2 \pm 2.3 \dagger$ & $3.9 \pm 0.3 \dagger$ & $157 \pm 5 \dagger$ \\
\hline \multirow[t]{2}{*}{$12 \mathrm{~h}$} & HR & $7.26 \pm 0.07 \dagger$ & $29.9 \pm 4$ & $40.3 \pm 3.6$ & $13.2 \pm 2.0^{*} \dagger$ & $-12.3 \pm 2.7^{*} \dagger$ & $4.9 \pm 1.1 \dagger$ & $148 \pm 3 \dagger$ \\
\hline & LR & $7.36 \pm 0.04 \dagger$ & $32.1 \pm 5$ & $39.8 \pm 4$ & $18.2 \pm 2.1 \dagger$ & $-6.7 \pm 2.0 \dagger$ & $3.8 \pm .3 \dagger$ & $157 \pm 5 \dagger$ \\
\hline \multirow[t]{2}{*}{$24 \mathrm{~h}$} & HR & $7.28 \pm 0.08 \dagger$ & $30.9 \pm 6 \dagger$ & $39.8 \pm 6.3$ & $13.9 \pm 2.2^{*} \dagger$ & $-11.7 \pm 3.1^{*} \dagger$ & $4.8 \pm 1.3 \dagger$ & $145 \pm 8^{*}+$ \\
\hline & LR & $7.37 \pm 0.03 \dagger$ & $37.6 \pm 5.7 \dagger$ & $36.4 \pm 4.8$ & $21,1 \pm 2.7^{*} \dagger$ & $-3.7 \pm 2.1^{*} \dagger$ & $3.5 \pm 0.3 \dagger$ & $155 \pm 3 \dagger$ \\
\hline \multirow[t]{2}{*}{$48 \mathrm{~h}$} & HR & $7.33 \pm 0.05$ & $31.3 \pm 5.9$ & $41 \pm 5$ & $16.2 \pm 1.3 \dagger$ & $-8.4 \pm 0.1 \dagger$ & $4,1 \pm 1.0$ & $154 \pm 1$ \\
\hline & LR & $7.36 \pm 0,04$ & $34.7 \pm 4.5$ & $36 \pm 6.9$ & $19.3 \pm 1.6 \dagger$ & $-5.4 \pm 1.8 \dagger$ & $3.8 \pm 0.3$ & $156 \pm 3$ \\
\hline
\end{tabular}

as a consequence of edema [11]. It is suggested that the fluid accumulation in the HRG happened due to the association of several factors, such as increased hydrostatic pressure $[5,7,10]$. Hypoalbuminemia [3,6] and vasculitis [7], which could lead to 
pleural effusion and ascites. Hypoalbuminemia per se does not cause pulmonary interstitial edema [6].

We understand that the fluid therapy rates must be individualized and tailored to each patient and constantly reevaluated and reformulated according to changes in status [13]. However for the purpose of the study it was necessary to set a fluid therapy protocol. Despite the expectation that increased fluid infusion might accelerate the electrolyte excretion of metabolites, the high rates of crystalloid solution infusion did not stabilize azotemia and the water-electrolyte balance faster; in fact it led to a fluid overload.

In conclusion, the infusion of high fluid rates in cats after a urethral obstruction episode must be undertaken with caution since this could lead to the death of a patient due to the occurrence of pleural effusion and the absence of electrolyte balance and glomerular filtration rate restoration.

\section{References}

1. Rieser TM. Urinary tract emergencies. Vet Clin North Am Small Anim Pract. 2005;35(2):359-373. doi:10.1016/j.cvsm.2004.12.001.

2. Bartges JW, Finco DR, Polzin DJ, Osborne CA, Barsanti JA, Brown SA Pathophysiology of urethral obstruction. Vet Clin North Am Small Anim Pract. 1996;26(2):255-264.

3. Hostutler RA, Chew DJ, DiBartola SP. Recent concepts in feline lower tract disease. Vet Clin North Am Small Anim Pract 2005;35(1):147170. doi:10.1016/j.cvsm.2004.08.006.

4. Polzin DJ, Osborne CA, Bartges JW. Management of postrenal azotemia. Vet Clin North Am Small Anim Pract. 1996;26:507- 513.
5. Mazzafero EM. Complications of fluid therapy. Vet Clin North Am Small Anim Pract. 2008;38(3):607-619. doi:10.1016/j.cvsm.2008.01.003.

6. Subramanian S, Zieldalski TM. Oliguria, Volume overload, $\mathrm{Na}+$ balance and diuretics. Crit Care Clin. 2005;21(2):291-303. doi:10.1016/j. ccc.2005.01.009.

7. Langston C. Managing fluid and electrolyte disorders in renal failure. Vet Clin North Am Small Anim Pract 2008;38(3):677-697. doi:10.1016/j.cvsm.2008.01.007.

8. Cunha MG, Freitas GC, Carregaro AB, Gomes K, Cunha JP, Beckmann $\mathrm{DV}$, et al. Renal and cardiorespiratory effects of treatment with lactated Ringer's solution or physiologic saline $(0.9 \% \mathrm{NaCl})$ solution in cats with experimentally induced urethral obstruction. Am J Vet Res. 2010;71(7):840-6. doi: 10.2460/ajvr.71.7.840.

9. Freitas GC, da Cunha MG, Gomes K, da Cunha JP, Togni M, Pippi NL, et al. Acid-base and biochemical stabilization in urethral obstruction male cats anesthetized with ketamine and diazepam or propofol. Canadian Journal of Veterinary Research. 2012;76(3):201-208.

10. Chan DL, Freeman LM, Rozanski EA, et al. Colloid osmotic pressure of parenteral nutrition components and intravenous fluids. J Vet Emerg Crit Care. 2001;11:269-73. doi: 10.1111/j.1476-4431.2001.tb00065.x.

11. Rudloff E, Kirby R. Crystalloid and colloid resuscitation. Vet Clin North Am Small Anim Pract. 2001;31(6):1207-29.

12. DiBartola, SP. Management of hypokalaemia and hyperkalaemia. J Feline Med Surg. 2001;3:181-183. doi:10.1053/jfms.2001.0147.

13. Davis H, Jensen T; Johnson A, Knowles P, Meyer R, Rucinsky R, et al. 2013 AAHA/AAFP Fluid Therapy Guidelines for Dogs and Cats. J Am Anim Hosp Assoc. 2013;49:149-159. Doi: 10.5326/JAAHA-MS-5868. 